\title{
Multi-residue determination of 10 selected new psychoactive sub- stances in wastewater samples by liquid chromatography-tandem mass spectrometry
}

\author{
Viola L. Borova ${ }^{a}$, Pablo Gago-Ferrero ${ }^{a}$, Constantinos Pistos ${ }^{b}$, Nikolaos S. Thomaidis ${ }^{a, *}$ \\ a Laboratory of Analytical Chemistry, Department of Chemistry, National and Kapodistrian University of Athens, Panepistimiopolis, 15771 Athens, Greece \\ ${ }^{\mathrm{b}}$ Laboratory of Forensic Medicine and Toxicology, School of Medicine, National and Kapodistrian University of Athens, Greece
}

\section{A R T I C L E I N F O}

\section{Article history:}

Received 29 January 2015

Received in revised form

24 June 2015

Accepted 26 June 2015

Available online 6 July 2015

\section{Keywords:}

NPSs

Synthetic cannabinoids

Sewage epidemiology

Wastewater

LC-MS/MS

\begin{abstract}
A B S T R A C T
New psychoactive substances (NPSs) have become increasingly popular in recent years. The analysis of these substances in influent wastewater (IWW) can be used to track their use in communities. In addition, an evaluation of the amount of NPSs released to the aquatic environment can be performed through the analysis of effluent wastewater (EWW). This study presents the development, validation and application of an analytical methodology, based on solid phase extraction (SPE) and liquid chromatography-tandem mass spectrometry (LC-MS/MS), for the determination of 10 NPSs in IWW and EWW. Synthetic cannabinoids, cathinones, piperazines and pyrrolidophenones are included among the target analytes. To the authors' knowledge, it is the first time that eight out of these substances (4'-methylpyrrolidinobutyrophenone (MPPP), a-pyrrolidinopentiophenone (a-PVP), 2-[(1S,3R)-3-hydroxycyclohexyl]-5-(2-methyl-2-octanyl) phenol (CP47,497), (1-naphthyl(1-pentyl-1H-indol-3-yl) methanone (JWH-018), (1-butyl-1H-indol-3-yl)(1-naphthyl) methanone (JWH-073), (4-ethyl-1-naphthyl)(1pentyl-1H-indol-3-yl) methanone (JWH-210), (4-methyl-1-naphthyl) (1-pentyl-1H-indol-3-yl) methanone (JWH-122) and 2-(2-methoxyphenyl)-1-(1-pentyl-1H-indol-3-yl) ethanone (JWH-250)) are investigated in wastewater. The optimized conditions for the analysis of this set of compounds included a SPE clean-up step using a polymeric sorbent and the use of a pentafluorophenyl (PFP) chromatographic column. Despite the broad range of physicochemical properties of the analytes the method allowed acceptable absolute recoveries (40-109\%) for all the studied compounds at different levels of concentration. Low method limits of detection (MLODs) were achieved, ranging between 0.3 and $10 \mathrm{ng} / \mathrm{L}$ except for BZP and CP47,497 (20 and $23 \mathrm{ng} / \mathrm{L}$, respectively), allowing a reliable and accurate quantification of the analytes. The method was successfully applied to the analysis of IWW and EWW samples from five wastewater treatment plants (WWTPs) located in Santorini Island (a highly touristic resort in Greece). Four out of 10 compounds (a-PVP, CP47,497, JWH-122 and JWH-210) were detected at least in one sample, being the first evidence of their presence in wastewater. CP47,497 was the most ubiquitous and abundant compound, showing concentrations up to $634 \mathrm{ng} / \mathrm{L}$ in some cases.
\end{abstract}

(c) 2015 Elsevier B.V. All rights reserved.

\section{Introduction}

In recent years, a high number of new substances, commonly named as new psychoactive substances (NPSs), have been appeared on the market. According to the definition provided by EMCDDA, NPSs are new narcotic or psychotropic drugs, in pure form or in preparation, that are not controlled by the 1961 United Nations Single Convention on Narcotic Drugs or the 1971 United Nations Convention on Psychotropic Substances, but which may

\footnotetext{
* Corresponding author. Fax: +30 2107274750.

E-mail address: ntho@chem.uoa.gr (N.S. Thomaidis).
}

pose a public health threat comparable to that posed by substances listed in these conventions (Council Decision 2005/387/ JHA) [1]. NPSs comprise a broad range of substances, including synthetic cannabinoids, cathinones, piperazines, tryptamines, amphetamine derivatives or pyrrolidinophenones. These compounds are often presented under "innocent" appearances (house scents, herbal mixtures, bath salts, or incenses) and have found a wide and efficient distribution mechanism through the "e-commerce" or specialized shops. These products claim to contain only "non-illegal" compounds and consequently have no limitations in their commercial distribution, although they exhibit important psychoactive effects [2,3]. The purpose of these substances is mainly to simulate the effects of common drugs of abuse, 
Table 1

Selected new psychoactive substances (NPSs), experimental ESI-MS/MS parameters, proposed product ions and predicted $\log P$ values.

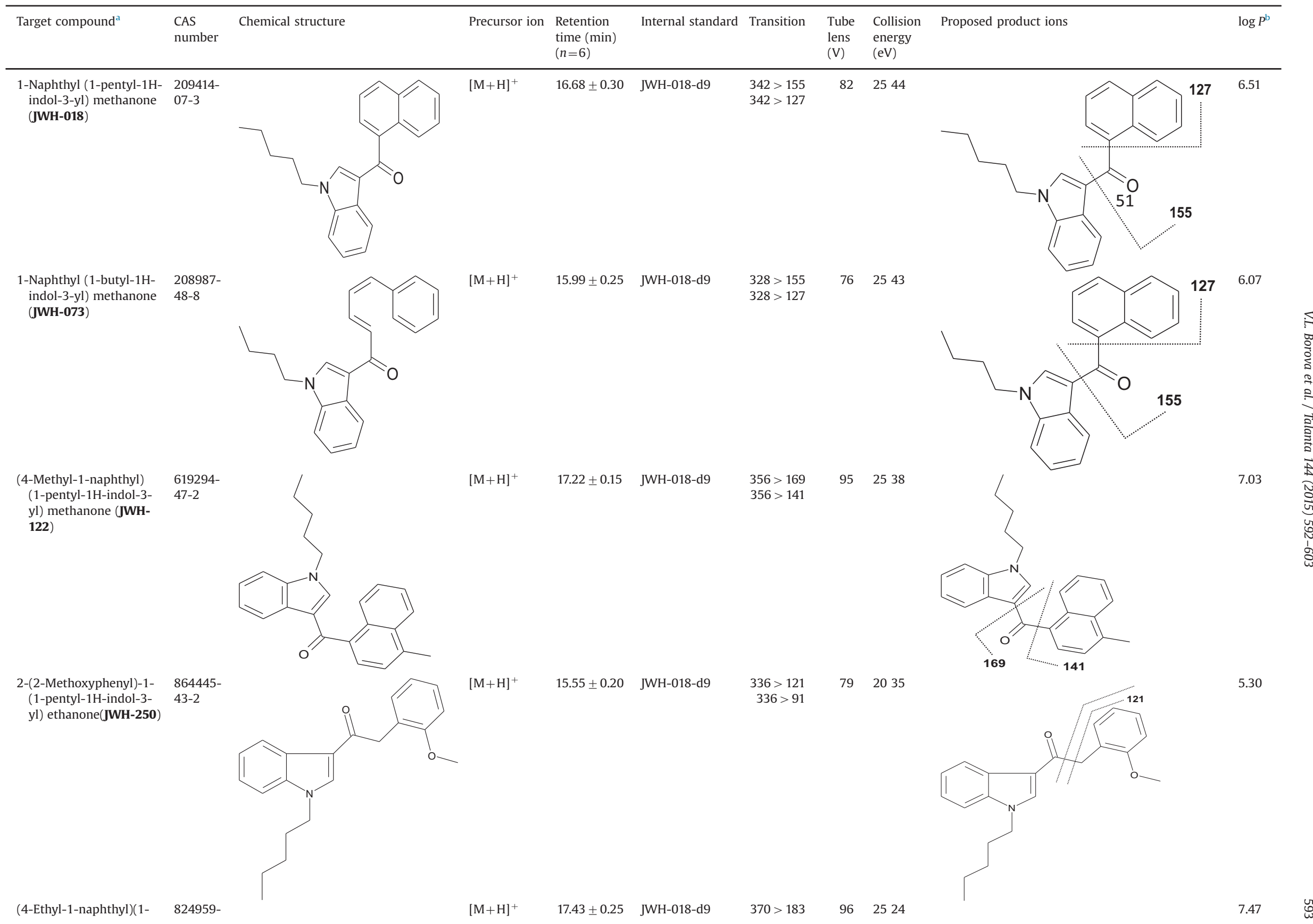




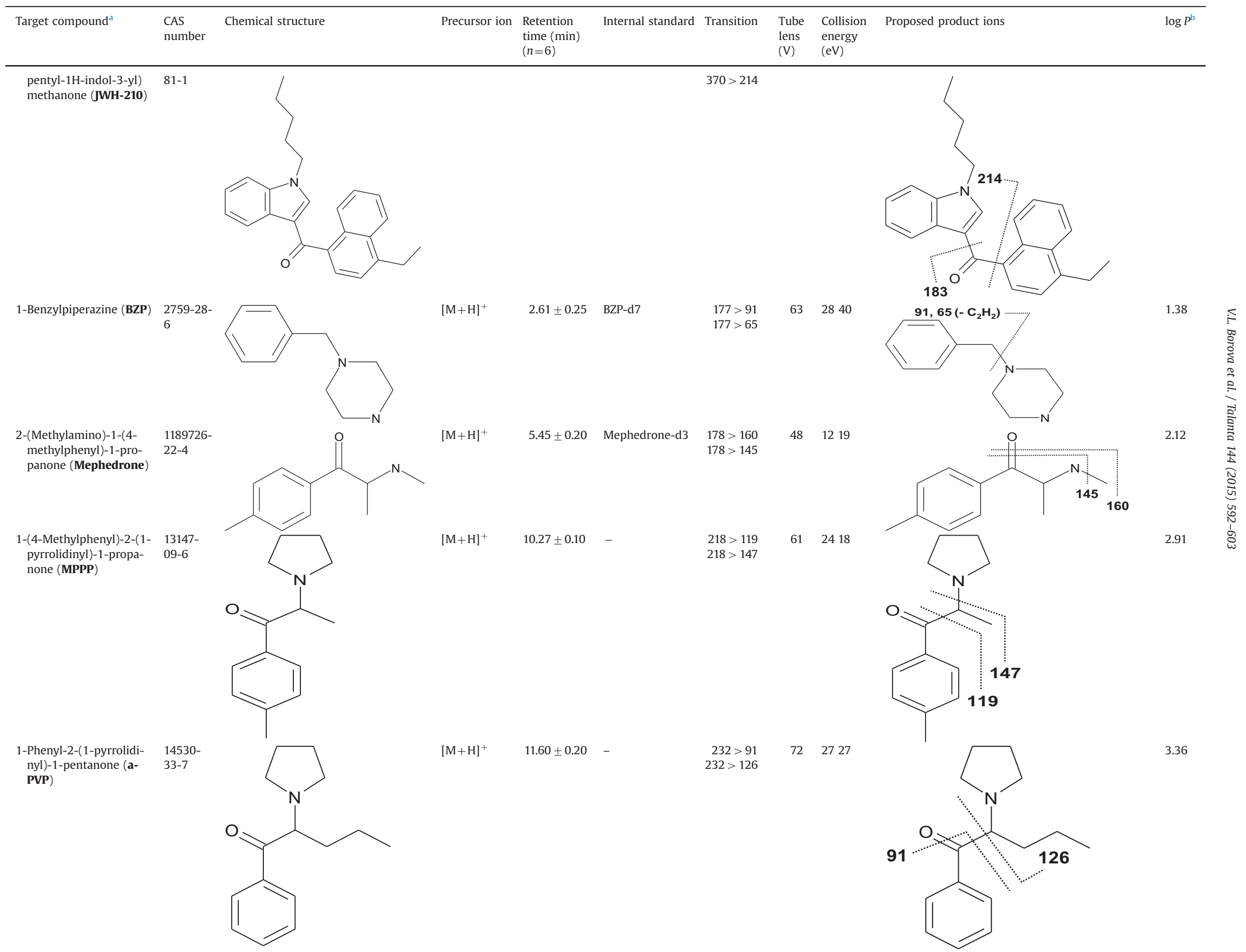


sometimes by simply adding or changing a functional group in the original drug molecule $[3,4]$. Consequently, they have similar pharmacological properties to the popular stimulants cocaine, amphetamines, 3,4-methylenedioxy-N-methylamphetamine (MDMA) or tetrahydrocannabinol (THC) [5-9]. Important toxicity effects have also been associated with the recreational use of these drugs [10-14]. The pattern of use and prevalence of NPSs and their control status are different depending on the country, but it is clear that both consumption and the number of consumed substances are increasing fast. This trend can be illustrated through the rise in notifications of new substances to the EU early warning system (EWS), from just 14 in 2005 to 101 in 2014 [15]. Another example can be found in the fact that the number of monitored synthetic cannabinoids, the largest chemical group of NPSs, has increased from 30 in 2012 to 134 in 2014 [15].

The information on the use of drugs of abuse and NPSs among the population can be obtained from self-report data (mainly from users), questionnaires, police seizures and through chemical analysis of drug residues in legal and illegal products (herbal, powders, tablets, paraphernalia), urine, blood, serum and hair samples [16]. However, highly valuable information can be obtained when the above epidemiological data is combined with the chemical analysis of urban wastewater. The estimation and comparison of community drug use through the analysis of selected drug biomarkers in sewage is rapidly being established as an effective monitoring tool $[3,17]$. Therefore, the development of accurate and sensitive methodologies for the analysis of NPSs in wastewater is an urgent need in order to obtain a real picture on the consumption and trends of these substances.

Although there are some approaches to determine qualitatively (and in some cases quantitatively) NPSs in body samples (blood, urine or hair, among others) [18], the methodologies for the quantitative determination of these substances in wastewater are scarce. Baker and Kasprzyk-Hordern developed a LC-MS/MS multiresidue method for the analysis of 65 stimulants, including some NPSs such benzylpiperazine (BZP), included in this study, which was detected in IWW and EWW from the U.K. with mean concentrations of 24.5 and $30.9 \mathrm{ng} / \mathrm{L}$, respectively [19]. It is worth mentioning that BZP was also detected in river water with a mean concentration of $26.0 \mathrm{ng} / \mathrm{L}$ [19]. A LC-MS/MS based method for simultaneous determination in wastewater of 14 biomarkers specific to synthetic cannabinoids and amphetamine-like substances was developed by Reid et al. [5]. Three of the 14 analytes were detected in sewage from Norwegian cities, being the metabolite of JWH-018, JWH-018N-5-hydroxypentyl, the most ubiquitous, ranging from 63 to $160 \mathrm{ng} / \mathrm{L}$. Mwenesongole et al. used gas chromatography-mass spectrometry (GC-MS) for the analysis in wastewater of 25 drugs from different classes, including mephedrone and BZP [20]. In that study, mephedrone was detected in wastewater from Cambridge (U.K.) at a very high concentration $(0.5 \mathrm{mg} /$ L) while BZP was not detected. Van Nuijs et al. [21] included mephedrone for the first time in wastewater analysis, although this substance was not detected in the monitored wastewater treatment plants (WWTPs) of Belgium. Chen et al. [10] determined mephedrone and BZP in wastewater from Australia using LC-MS/ MS. This study showed that a decline in the MDMA use was associated with some increases in the use of these compounds, as well as other synthetic stimulants, in a localized manner.

The present study aims to develop and validate a highly sensitive and efficient methodology based on LC-MS/MS for the quantitative determination of 10 relevant NPSs from different representative families in wastewater. The selected compounds are presented in Table 1. These substances have been detected in seizures of tablets of synthetic drugs in Greece [22,23]. Moreover these compounds have been previously detected in human samples (urine, blood, serum or hair) [24-29]. Some compounds (e.g.

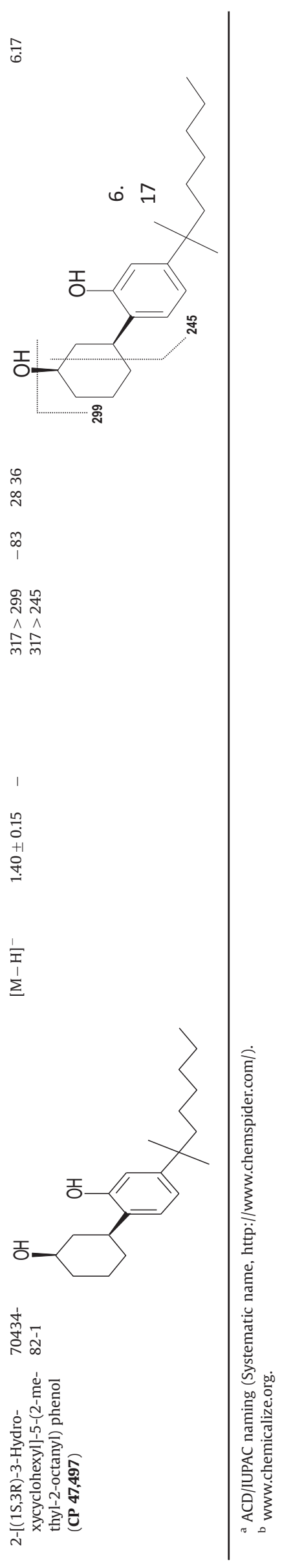


mephedrone and BZP) are controlled according to the Greek legislation but most NPSs, including all the synthetic cannabinoids, are not [23]. The LC-MS/MS optimization and performance, sample preparation and method validation were discussed in detail. The developed methodology was applied to the determination of NPSs in IWW and EWW of different WWTP of the touristic island of Santorini (Greece). To the authors' knowledge, this is the first time that the compounds 4'-methylpyrrolidinobutyrophenone (MPPP), a-pyrrolidinopentiophenone (a-PVP), and the synthetic cannabinoids 2-[(1S,3R)-3-hydroxycyclohexyl]-5-(2-methyl-2-octanyl) phenol (CP47,497), (1-naphthyl(1-pentyl-1H-indol-3-yl) methanone (JWH-018), (1-butyl-1H-indol-3-yl)(1-naphthyl) methanone (JWH-073), (4-ethyl-1-naphthyl)(1-pentyl-1H-indol-3-yl) methanone (JWH-210), (4-methyl-1-naphthyl)(1-pentyl-1H-indol-3-yl) methanone (JWH-122) and 2-(2-methoxyphenyl)-1-(1-pentyl-1Hindol-3-yl) ethanone (JWH-250) are investigated in environmental samples, expanding the knowledge on the occurrence of NPSs in wastewater, an indicator of the use of these substances in the community.

\section{Materials and methods}

\subsection{Standards and materials}

Structures, CAS numbers and predicted $\log P$ values of the target compounds are summarized in Table 1. BZP, the deuterated standard benzylpiperazine- $\mathrm{d}_{7}$ (BZP-D7), JWH-018, JWH-073, mephedrone (2-(methylamino)-1-(4-methylphenyl)-1-propanone) and mephedrone-d3 were purchased from Cerilliant Corp. (Round Rock, TX, USA), as certified solutions. MPPP, a-PVP, JWH-210 and the deuterated compound JWH-018-d9 were obtained from Cayman Chemical Company (East Ellsworth, MI, USA) as certified solutions and crystallized solids. JWH-122 was purchased from LGC (Mercatorstrass, Germany), JWH-250 from Toronto Research Chemicals (Toronto, Canada, USA) and CP 47,497 from THC Pharm (Frankfurt, Main, Germany) as methanol solution of $98.6 \%$ purity.

For the infusion experiments, solutions of individual standards, including internal standards (IS), were prepared at concentrations of $1.5 \mathrm{mg} / \mathrm{L}$ in methanol (MeOH):Milli-Q water with $0.05 \% \mathrm{v} / \mathrm{v}$ formic acid (50:50, v/v), just before the experiments. Working solutions were prepared daily by appropriate dilution of the mixture stock standard $(1.0 \mathrm{mg} / \mathrm{L})$ and IS solutions $(1.0 \mathrm{mg} / \mathrm{L})$ in $\mathrm{MeOH}$. Calibration standards were prepared by serial dilution of the mixed working solution using Milli-Q water resulting in individual concentrations ranging from 200 to $80,000 \mathrm{ng} / \mathrm{L}$. All stock and working solutions were stored in dark glass bottles in the dark at $-20{ }^{\circ} \mathrm{C}$. $\mathrm{MeOH}$, acetonitrile (ACN) and ethyl acetate (EtAc) (HPLC gradient solvent, 99.9\% purity, Lichrosolv) and hydrochloric acid (37\%) were purchased from Merck (Darmstadt, Germany). High purity water was prepared using a Milli-Q water purification system (Millipore Direct-Q UV, Bedford, MA, USA). Formic acid (98\% purity, HPLC-grade) was obtained from Sigma-Aldrich (Schweiz, Switzerland). Ammonium hydroxide solution was prepared using ammonia (25\%), which was purchased from Panreac (Barcelona, Spain). Strata-X (200 mg/6 mL) and Strata-XC (200 mg/ $6 \mathrm{~mL}$ ) cartridges and syringe filters (Phenex RC, $4 \mathrm{~mm}$, pore size $0.2 \mu \mathrm{m}$ ) were obtained from Phenomenex (Torrance, CA, USA). PolyClean 2H (200 mg/6 mL) and ATOLL XC (200 mg/6 mL) were purchased from Interchim (Montlucon, France). Lichrolut EN (200 mg/3 mL), Lichrolut EN (bottom, $100 \mathrm{mg}$ )/RP-18 (top, $200 \mathrm{mg})(6 \mathrm{~mL})$, Lichrolut SCX $(200 \mathrm{mg} / 3 \mathrm{~mL})$ and Lichrolut TSC (300 mg/3 mL) were obtained from Merck (Darmstadt, Germany). Additionally, Isolute C18 (EC) $(200 \mathrm{mg} / 6 \mathrm{~mL})$ were obtained from Biotage (Uppsala, Sweden) and glass fiber filters (GFF, pore size $0.7 \mu \mathrm{m}$ ) used in wastewater filtration were obtained from
Millipore (Cork, Ireland).

\subsection{Sampling collection and sample preparation}

Samples were obtained from five wastewater treatment plants of Santorini Island, a highly touristic Greek island located in the southern Aegean Sea. Santorini has a population of 15,550 inhabitants (according with the census of 2011), but it suffers a great increase of population during summer since it is a very important touristic center. This touristic island provides a good example to evaluate the use of NPSs in touristic places where nightlife is also very popular. For this purpose, IWW and EWW samples (grab samples) were collected from five WWTPs in different locations of Santorini Island. Sampling locations as well as the main characteristics of the WWTPs (all of them equipped with conventional activated sludge secondary treatment) are described in detail in a previous study [30]. These samples were collected in July 2013. Pooled IWW and also pooled EWW samples (separately) were used for the validation of the method.

In order to estimate the daily variation of the usage of NPSs in the island, IWW samples (grab samples) were collected from the WWTP of Fira (the one which serves the largest population) during seven consecutive days (from 23/07/2013 to 29/07/2013)

Wastewater samples (both IWW and EWW) were collected in plastic (PET) bottles, and maintained in the dark under freezing conditions until their arrival at the laboratory. Next, $50 \mathrm{~mL}$ of each sample were vacuum filtered through a disposable $1000 \mathrm{~mL}$ capacity stericup funnel using GFF $(0.7 \mu \mathrm{m})$. Once filtered, samples were acidified with $\mathrm{HCl}(1 \mathrm{M})$ to $\mathrm{pH} 2.5( \pm 0.1)$, kept at $4{ }^{\circ} \mathrm{C}$ and extracted within $20 \mathrm{~h}$. No degradation of the compounds was observed during this storage period.

\subsection{Solid phase extraction}

Analytes were extracted and preconcentrated from wastewater samples by solid phase extraction (SPE). SPE experiments were performed using a VARIAN (Vac Elut SPS 24) manifold and PolyClean $2 \mathrm{H}$ (200 mg) cartridges, with spherical pure mixed polymer sorbent.

In the optimized method cartridges were conditioned with $6 \mathrm{~mL}$ of $\mathrm{MeOH}$ and $6 \mathrm{~mL}$ of acidified ultrapure water (pH 2.5 with $\mathrm{HCl} 1 \mathrm{M}$ ). Next, $50 \mathrm{~mL}$ of the samples passed through the cartridges at a rate of $1 \mathrm{~mL} / \mathrm{min}$. Cartridges were washed with $3 \mathrm{~mL}$ of ultrapure water $(\mathrm{pH} \mathrm{2.5)}$ at the same flow rate and subsequently dried under vacuum for $30 \mathrm{~min}$ and $10 \mathrm{psi}$. Analytes were eluted with $2 \times 2 \mathrm{~mL}$ of $\mathrm{MeOH}$ and $4 \times 2 \mathrm{~mL} \mathrm{MeOH/EtAc} \mathrm{(50:50).} \mathrm{The}$ extracts were evaporated to dryness at $40{ }^{\circ} \mathrm{C}$ under a gentle stream of nitrogen and further reconstituted in $500 \mu \mathrm{L}$ of $\mathrm{MeOH} /$ water (60:40) followed by 1 min vortex stirring. Finally, the extracts were filtered through $0.2 \mu \mathrm{m}$ RC syringe filters and then transferred to glass vials for immediate LC-MS/MS analysis.

\subsection{LC-tandem mass spectrometry}

Instrumental analysis was conducted using an Accela gradient UHPLC pump equipped with an Accela autosampler system coupled to a TSQ Quantum Access triple-quadrupole mass spectrometer, both from Thermo Electron Corporation (Thermo, San Jose, CA, USA). The triple quadrupole mass spectrometer was equipped with an electrospray ionization source (Thermo IonMAX). In the optimized LC method the chromatographic separation of the compounds was achieved on a Kinetex, pentafluorophenyl (PFP) reversed-phase fused-core column $(50 \mathrm{~mm} \times 2.10 \mathrm{~mm}, 1.7 \mu \mathrm{m})$ equipped with a guard PFP column $(4 \mathrm{~mm} \times 20 \mathrm{~mm})$, both from Phenomenex (Torrance, USA). For the analysis under positive ionization mode (PI), the mobile phase was composed by $0.2 \% \mathrm{v} / \mathrm{v}$ 
formic acid in Milli-Q water (A) and $\mathrm{MeOH}$ (B) as organic phase. The adopted elution gradient starts with $40 \%$ of $\mathrm{MeOH}$ and keeps constant during $3 \mathrm{~min}$. After that it increases linearly to $100 \%$ in $15 \mathrm{~min}$. Pure organic conditions were kept constant for $10 \mathrm{~min}$ and finally initial conditions were reached and keep constant for 5 min for column equilibration. The total run time for each injection was $30 \mathrm{~min}$. The column temperature was set to $25^{\circ} \mathrm{C}$. The determination of $\mathrm{CP} 47,497$ was performed under negative ionization mode (NI), also on the Phenomenex ${ }^{\mathrm{TM}}$ Kinetex PFP column. The mobile phase was composed by $\mathrm{MeOH}$ and $\mathrm{ACN}$. The isocratic program consists of $90 \%$ of $\mathrm{MeOH}$ and $10 \% \mathrm{ACN}$ for $8 \mathrm{~min}$. The mobile phase flow rate was set to $100 \mu \mathrm{L} / \mathrm{min}$ and the injection volume was $10 \mu \mathrm{L}$ in both ionization modes.

Identification and quantification were performed under selected-reaction monitoring (SRM) mode. Two major products ions of the precursor molecular ion were monitored per analyte. The most abundant transition was used for quantification, whereas the second most abundant was used for confirmation. Fragmentation
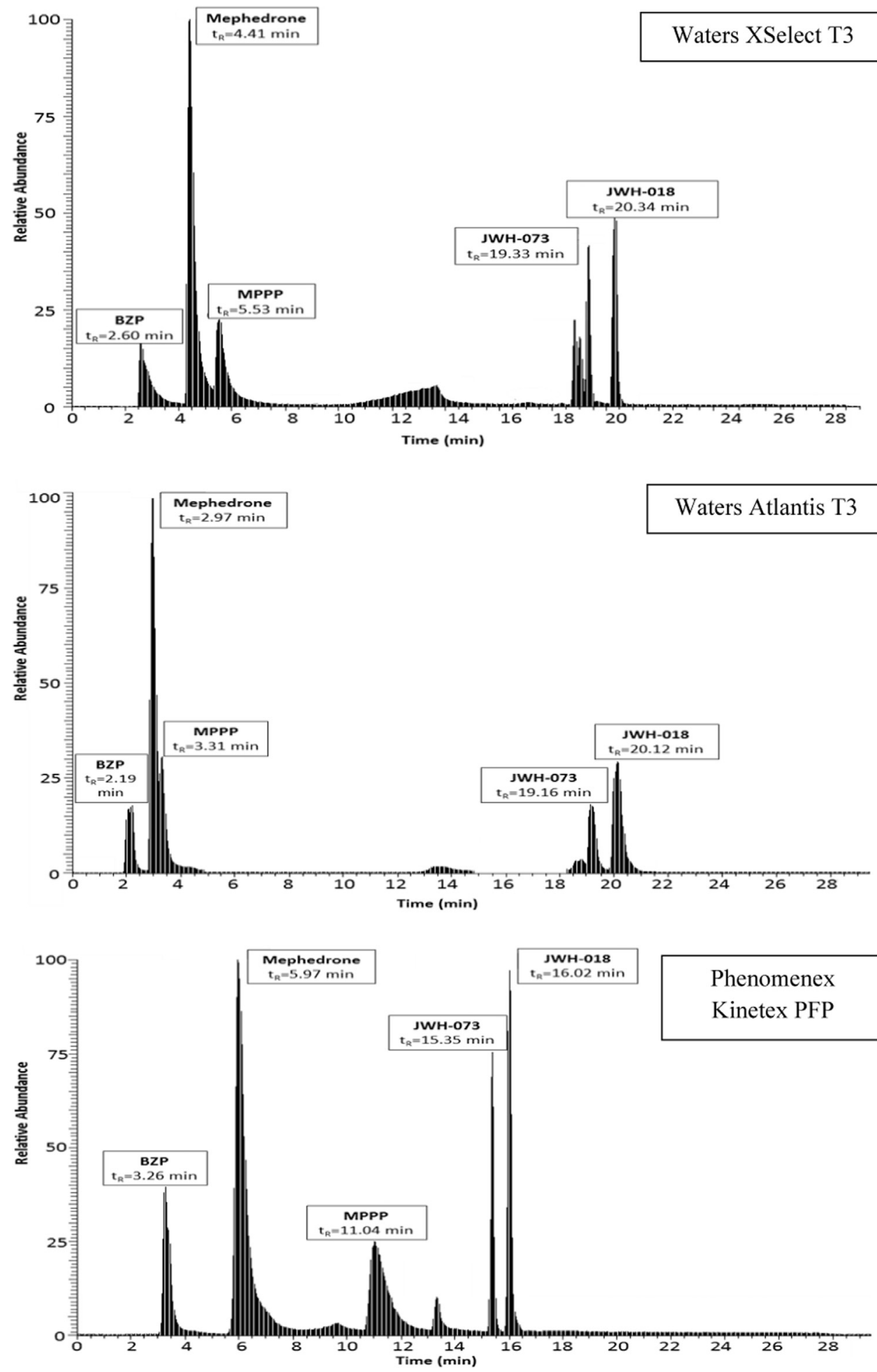

Fig. 1. Comparison of the total Ion Chromatograms (TIC) of new psychoactive substances using three different stationary phases (concentration: $80 \mathrm{ng} / \mathrm{L}$ ). 

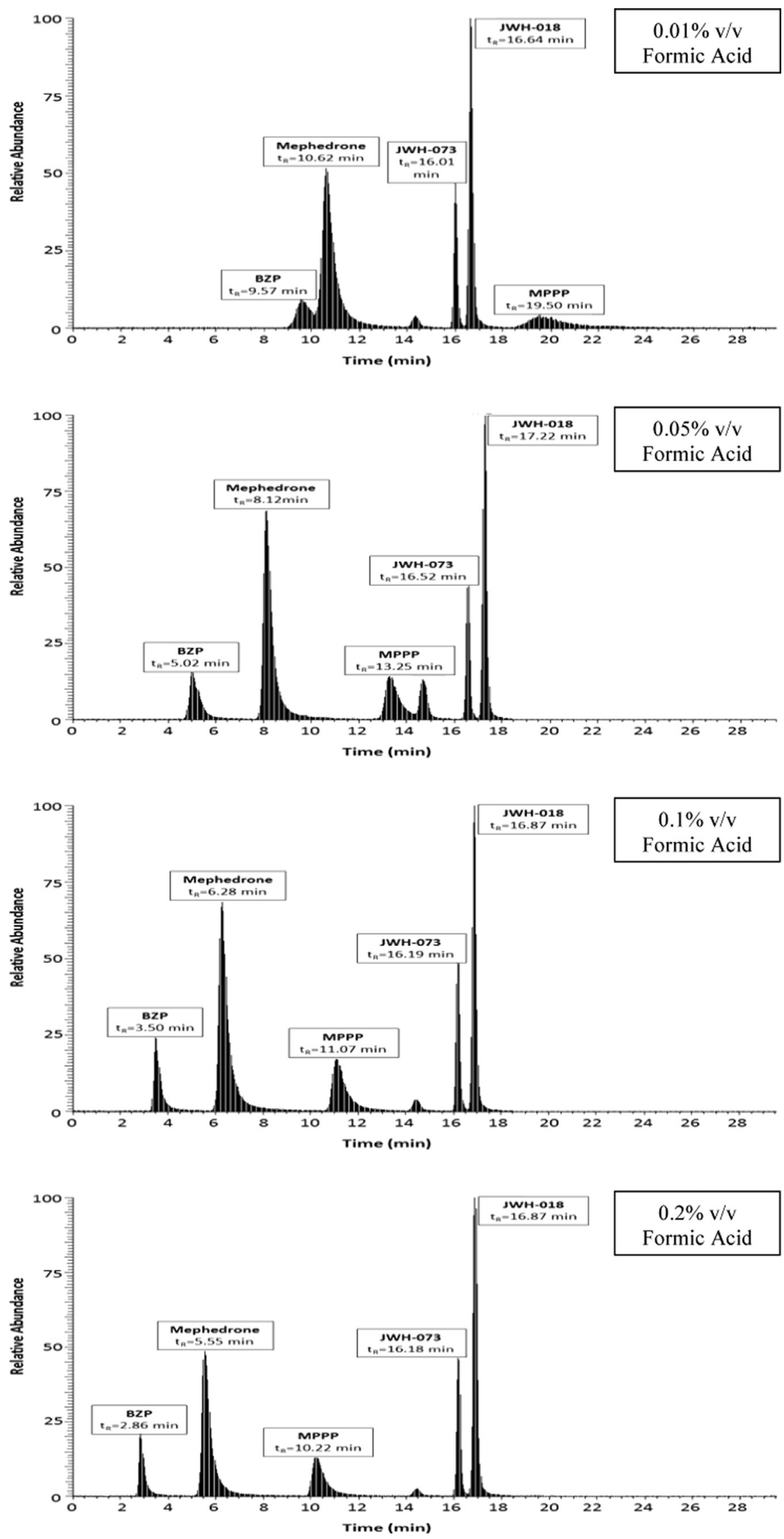

Fig. 2. Optimization of the formic acid concentration in the mobile phase. 
voltage and collision energy were optimized for each transition by infusion of individual standards of each compound. The used ESI conditions for both PI and NI mode are reported in detail in a previous study [30], as they proved to be optimal for the determination of the target analytes, as well.

Chromatographic retention times $\left(t_{\mathrm{R}}\right)$, SRM transitions, cone voltages, collision energies and the proposed fragmentation ions are shown in Table 1. Instrument control and data acquisition and evaluation were performed using Xcalibur software, version 2.1 (Thermo Electron Corporation).

\section{Results and discussion}

\section{1. $L C-M S / M S$ optimization}

Three different reversed phase columns, Atlantis T3-C18 $(100 \mathrm{~mm} \times 2.1 \mathrm{~mm}, 3 \mu \mathrm{m})$ and XSelect T3-C18 $(100 \mathrm{~mm} \times 2.1 \mathrm{~mm}$, $2.5 \mu \mathrm{m}$ ) from Waters (Milford, MA, USA), and a pentafluorophenyl (PFP) column $(50 \mathrm{~mm} \times 2.1 \mathrm{~mm}, 1.7 \mu \mathrm{m})$ from Phenomenex, were compared in terms of chromatographic peak shape and resolution for the compounds BZP, JWH-073, JWH-018, mephedrone and MPPP. The synthetic cannabinoids JWH-122, JWH-210 and JWH250 , with structures and physicochemical properties very similar to their analogs JWH-073 and JWH-018, as well as the pyrrolidinophenone a-PVP, very similar to MPPP, were further added to the final methodology. Column selection for chromatographic analysis was an important step since the structures and physicochemical properties of the different families of compounds are very different among them. Atlantis T3 and XSelect T3 have different base particles (silica particles and high strength silica particles, respectively) and the same ligand (trifunctional alkyl C18), whereas PFP has a core shell silica and a pentafluorophenyl ligand. All three columns are appropriate according to the manufacturer for the analysis of general mixtures containing both polar and non-polar compounds [31,32]. As it is shown in Fig. 1, the obtained chromatograms were very different when using C18 or PFP, due to the differences among these stationary reverse phases. Stronger retention due to the $p-p$ bonding was observed for the polar compounds when using a PFP column compared to the C18 columns. On the contrary, the non-polar synthetic cannabinoids were eluted faster with a PFP column compared to the C18 columns. The difference in the base particle properties between XSelect and Atlantis columns resulted in different chromatographic performance as can be observed in Fig. 1. Increased retention, higher resolution and better peak shape for the polar compounds were achieved with XSelect compared to Atlantis T3, whereas the peak shape of the non-polar compounds was improved with Atlantis T3. Nonetheless, both C18 columns presented peak area asymmetry with a peak fronting effect (particularly relevant for the more polar compounds) and also lower sensitivity compared with the PFP column. PFP column was more appropriate for all compounds, showing better chromatographic performance, especially for polar compounds containing $-\mathrm{NH}_{2}$ or $-\mathrm{NH}-$ groups, providing higher sensitivity and resolution and more symmetric peaks. Therefore, PFP column was chosen to perform the experiments.

$\mathrm{MeOH}$ and Milli-Q water with formic acid was chosen as mobile phase since this combination showed the best chromatographic performance, when working in PI mode in previous studies, dealing with psychoactive drugs [30]. Methanol and Milli-Q water $(0.05 \% \mathrm{v} / \mathrm{v}$ formic acid) was used in the experiments for the column selection. Since the proportion of formic acid in the aqueous phase may play an important role in the peak shape and particularly in peak intensity [21], this parameter was further optimized. Different concentrations of formic acid (FA) in Milli-Q water $(0.01 \% \mathrm{v} / \mathrm{v}, 0.05 \% \mathrm{v} / \mathrm{v}, 0.1 \% \mathrm{v} / \mathrm{v}$ and $0.2 \% \mathrm{v} / \mathrm{v})$ were tested.
These experiments are summarized in Fig. 2, where the total ion chromatograms of the target compounds are shown with different FA concentrations. It can be observed how the different FA concentration affects retention time, peak shape and peak area (not shown in Fig. 2) of the analytes. At low concentrations of FA, polar compounds (BZP, MPPP, a-PVP, mephedrone) showed stronger retention while at higher FA concentration in the mobile phase resulted in faster elution, sharper peaks, increased resolution and enhanced sensitivity. On the contrary, retention time of the nonpolar synthetic cannabinoids remained stable, while peak area and peak shape were improved significantly. A representative example is MPPP, whose peak area was increased more than 50\%, its peak became sharper, while its retention time decreased by increasing the concentration of FA. A concentration of $0.2 \% \mathrm{v} / \mathrm{v}$ of formic acid in the aqueous phase was finally chosen.

In the NI mode, the best chromatographic conditions were achieved using $\mathrm{MeOH}$ and $\mathrm{ACN}$ in isocratic mode without the use of additional modifier. Column operational temperature was set to $25{ }^{\circ} \mathrm{C}$ and was not optimized since previous experiments showed no significantly effects in the chromatographic performance of similar analytes [30].

Figs. S1 and S2 (supplementary material) show the total ion chromatograms and the extracted ion chromatograms for the 10 target NPSs analyzed under optimized conditions in both PI and NI mode. The final chromatographic retention times are displayed in Table 1.

Table 1 also summarizes the optimized values of MS/MS parameters for the target compounds. Cone voltage and collision energies were optimized for every compound through infusion experiments at a concentration of $1.5 \mathrm{mg} / \mathrm{L}$. For all the compounds determined in $\mathrm{Pl}$ mode the precursor ion was $[\mathrm{M}+\mathrm{H}]^{+}$and in the NI mode the precursor ion corresponded to the deprotonated molecule $[\mathrm{M}-\mathrm{H}]^{-}$. Product ions were proposed for all transitions and are summarized in Table 1 . Similar fragmentation pathway was observed for JWH-018, JWH-122 and JWH-210. For these compounds the main transition, used for quantification, corresponded to the loss of $186 \mathrm{Da}\left([\mathrm{M}+\mathrm{H}]^{+} \rightarrow\left[\mathrm{M}-\mathrm{C}_{13} \mathrm{H}_{16} \mathrm{~N}\right]^{+}\right)$. In the case of JWH-250 the quantification transition occurred through the loss of $214 \mathrm{Da}\left([\mathrm{M}+\mathrm{H}]^{+} \rightarrow\left[\mathrm{M}-\mathrm{C}_{14} \mathrm{H}_{16} \mathrm{NO}\right]^{+}\right)$and for JWH-073 through the loss of $172 \mathrm{Da}\left([\mathrm{M}+\mathrm{H}]^{+} \rightarrow\left[\mathrm{M}-\mathrm{C}_{12} \mathrm{H}_{14} \mathrm{~N}\right]^{+}\right)$.

For the piperazine derivative BZP the quantification transition was formed by the loss of the piperazine group. The first transition of mephedrone was formed by the loss of a water molecule, whereas the second one occurred by a subsequent loss of $-\mathrm{CH}_{3} \bullet$. MPPP and a-PVP belong to the same group of pyrrolidinophenones, although their fragmentation patterns are different. For MPPP the first transition corresponded to $[\mathrm{M}+\mathrm{H}]^{+} \rightarrow$ $\left[\mathrm{M}-\mathrm{C}_{6} \mathrm{H}_{12} \mathrm{~N}\right]^{+}$and in the case of a-PVP to $[\mathrm{M}+\mathrm{H}]^{+} \rightarrow$ $\left[\mathrm{M}-\mathrm{C}_{8} \mathrm{H}_{15} \mathrm{NO}\right]^{+}$. CP47,497 is a cyclohexylphenol analog and can be ionized only under NI mode. Collision induced dissociation fragmentation was dominated by the loss of a hydroxyl group. All the above proposed fragmentation patterns are in agreement with previous publications [33-35].

\subsection{Solid-phase extraction (SPE)}

SPE is a critical step and contribute significantly to the final performance of the analytical method. SPE was optimized by evaluating initially six NPSs. Subsequently, four additional compounds with similar structures and physicochemical properties were added to the final methodology, before the validation of the method was performed.

SPE was optimized through several preliminary experiments involving the type of sorbent and the elution conditions. Some of the tested cartridges consisted of strong cation exchange functionalized polymeric sorbents, including Strata-XC (200 mg), ATOLL 


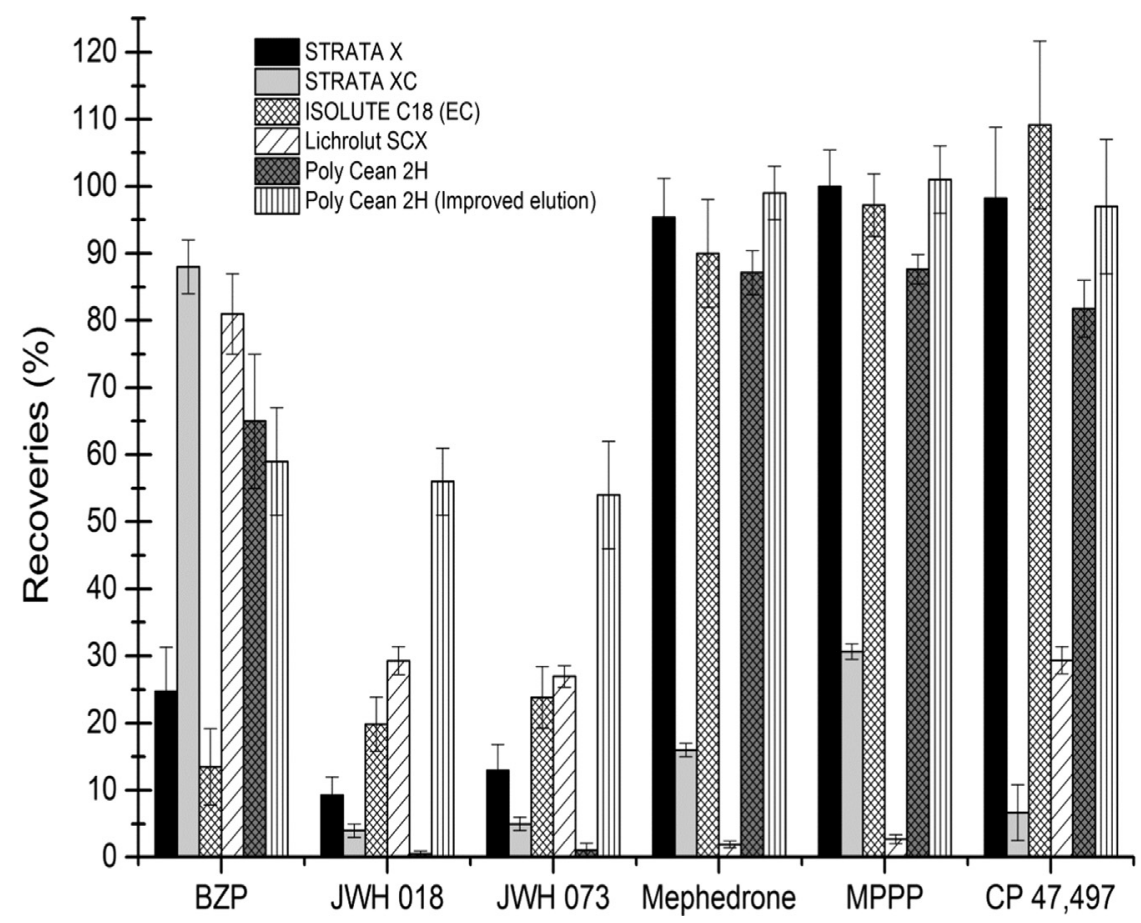

Fig. 3. Optimization of the solid phase extraction (SPE) procedure using different sorbents.

XC (200 mg), Lichrolut SCX (200 mg) and Lichrolut TSC (300 mg). These cartridges were equilibrated with $6 \mathrm{ml}$ of $\mathrm{MeOH}$ and $6 \mathrm{ml}$ of acidified Milli Q water and the elution of the compounds was achieved with basic methanol, initially following the procedure described in detail in a previous publication [30]. The other cartridges consisted of polymeric reversed phase and silica based sorbents including Strata-X (200 mg), PolyClean $2 \mathrm{H}(200 \mathrm{mg})$, Lichrolut EN (200 mg), Lichrolut EN (bottom, $100 \mathrm{mg}$ )/RP (top, $200 \mathrm{mg}$ ) and Isolute C18 (EC) $(200 \mathrm{mg})$. In this case the equilibration was performed with $6 \mathrm{ml}$ of methanol and $6 \mathrm{ml}$ of Milli Q water, whereas the elution was achieved with $6 \mathrm{ml}$ of methanol. The SPE optimization experiments were performed using a mixture of pooled IWW and EWW samples.

Fig. 3 shows the recoveries obtained with five different cartridges (the results for all the tested cartridges are displayed in Table S1, in the supplementary material). The cartridges including strong cation exchange groups (Strata XC and Lichrolut SCX) provided poor recoveries for all the evaluated compounds, showing values particularly low for compounds such as mephedrone or MPPP. However, these cartridges provided very good recoveries for the cationic compound BZP (with recovery rates up to $88 \%$ ). Polymeric cartridges showed relatively good recoveries for all compounds except for the synthetic cannabinoids. Among these cartridges, PolyClean $2 \mathrm{H}$ was the only one which provided good results for the polar compound BZP. Although PolyClean $2 \mathrm{H}$ provided very low recoveries for the studied synthetic cannabinoids, it was chosen for further optimization because of the hypothesis that this family of compounds was not eluted only with $6 \mathrm{~mL}$ of $\mathrm{MeOH}$ and it would be easy to improve the recovery rates by optimizing the elution step with stronger eluents. Stronger eluents were also tested with Strata XC cartridges, but, although the recoveries of synthetic cannabinoids improved slightly, the recoveries for the other compounds remained low. In order to elute the non-polar synthetic cannabinoids with PolyClean $2 \mathrm{H}$ cartridges, different combinations of eluents were tested. $\mathrm{MeOH}$ was combined with other solvents, including $A C N$, dichloromethane, EtAc and a mixture of MeOH/EtAc (1:1). ACN and dichloromethane did not improve significantly the recoveries. The elution with EtAC or with the mixture $\mathrm{MeOH} / \mathrm{EtAc}$ improved the results for synthetic cannabinoids, but resulted in lower extraction efficiency for other compounds. The best results were obtained eluting with $4 \mathrm{~mL}$ of $\mathrm{MeOH}$, followed by additional $8 \mathrm{~mL}$ of a mixture of MeOH/EtAc 1:1. Moreover, the results were slightly improved when using acidified water $(\mathrm{pH} 3$ ) during equilibration and washing steps. The values obtained with the optimized conditions are shown in Fig. 3 (Polyclean 2H improved elution).

Before LC-MS/MS injection, all the samples were filtered through a $0.2 \mu \mathrm{m}$ RC syringe filter for the removal of particles which may cause blockage of the column filter and reduce their life and efficiency [30]. RC filters were previously checked with standards and it was proved that they do not retain any of the compounds.

\subsection{Quantification and method validation}

Quantification of the target compounds in samples, based on peak areas, was performed by the internal standardization method, using spiked samples with the corresponding labeled analyte (IS). Three deuterated IS were used in order to compensate for signal suppression or enhancement of the analytes and/or low SPE recoveries. Table 1 shows the corresponding IS used for each analyte. The choice of JWH-018-d9 for all the synthetic cannabinoids was based on the similar structure and analytical response. Mephedrone and BZP deuterated internal standards were also used. Proper labeled standards for compensating the variations of the compounds a-PVP, MPPP and CP47,497 could not be found. However, due to their high absolute and reproducible recoveries, the quantification was performed by matrix-matched standards, without IS. The performance of the method was evaluated under the optimized conditions in terms of linearity range, detectability, trueness, accuracy and matrix effects.

The linearity of the method was studied for each compound by analyzing standard solutions six times at different concentrations, ranging from 200 to $80,000 \mathrm{ng} / \mathrm{L}$ ( 8 point calibration curve). The mean correlation coefficients $\left(r^{2}\right)$ of the calibration curves prepared in sample diluents were higher than 0.999 and showed good 
Table 2

Instrumental quality parameters of the LC-ESI-MS/MS determination of new psychoactive substances (NPSs).

\begin{tabular}{lcccc}
\hline & Linearity range $(\mathrm{ng} / \mathrm{L})$ & $R^{2}$ & ILODs $(\mathrm{ng} / \mathrm{L})$ & ILOQs $(\mathrm{ng} / \mathrm{L})$ \\
\hline JWH-018 & $200-80,000$ & 0.9994 & 50 & 160 \\
JWH-073 & $200-80,000$ & 0.9991 & 70 & 230 \\
JWH-210 & $200-80,000$ & 0.9995 & 40 & 140 \\
JWH-122 & $200-80,000$ & 0.9992 & 50 & 160 \\
JWH-250 & $200-80,000$ & 0.9996 & 60 & 190 \\
Mephedrone & $500-80,000$ & 0.9995 & 180 & 530 \\
BZP & $500-80,000$ & 0.9996 & 180 & 530 \\
MPPP & $500-80,000$ & 0.9997 & 200 & 620 \\
a-PVP & $500-80,000$ & 0.9994 & 200 & 620 \\
CP47,497 & $2500-80,000$ & 0.9995 & 800 & 2660 \\
\hline
\end{tabular}

linearity in the range $200-80,000 \mathrm{ng} / \mathrm{L}$ or $500-80,000 \mathrm{ng} / \mathrm{L}$ for all the compounds except for CP47,497, which showed a linearity range from 2500 to $80,000 \mathrm{ng} / \mathrm{L}$ (Table 2). Instrumental limits of detection and instrumental limit of quantification (ILOD and ILOQ respectively) were determined using diluted standard solutions (60\% $\mathrm{MeOH}$ and $40 \%$ Milli-Q water with $0.05 \% \mathrm{v} / \mathrm{v}$ formic acid). ILODs and ILOQs were calculated by dividing the standard deviation of the lowest concentration of standard solvent by the slope of the calibration curve. These results are summarized in Table 2, where ILODs ranging from 40 to $800 \mathrm{ng} / \mathrm{L}$ (injection $10 \mu \mathrm{L}$ ) can be observed. The method limits of detection (MLOD) and method limits of quantification (MLOQ) for both IWW and EWW were calculated by analyzing six times the lowest spiked concentration (for all of the compounds $10 \mathrm{ng} / \mathrm{L}$ ) and dividing its standard deviation by the slope of the calibration curve of spiked samples. The definition of these limits is based on the ability of the method to distinguish the signal of the analyte from the signal of the noise. These values are summarized in Table 3. MLOD values ranged from 0.3 to $5 \mathrm{ng} / \mathrm{L}$ in effluents for all the compounds except BZP and
CP47,497 (MLODs $15 \mathrm{ng} / \mathrm{L}$ and $18 \mathrm{ng} / \mathrm{L}$ respectively) and from 0.8 to $10 \mathrm{ng} / \mathrm{L}$ for all compounds in IWW, with the exception of BZP and CP47,497, with MLODs of $20 \mathrm{ng} / \mathrm{L}$ and $23 \mathrm{ng} / \mathrm{L}$, respectively. Trueness was assessed with recovery experiments in IWW and EWW samples. Extraction recoveries for target analytes were determined $(n=6)$ at two concentration levels, 10 and $800 \mathrm{ng} / \mathrm{L}$ in IWW and EWW. Recoveries were determined by comparing the concentrations obtained after the whole sample preparation with the initial spiking levels. As real samples may already contain target compounds, EWW pool samples and IWW pool samples, separately, were analyzed in order to determine their concentrations, which were afterwards subtracted from the spiked samples. Absolute recovery values are summarized in Table 3 . Values ranged from $54 \%$ to $109 \%$ in IWW and from $40 \%$ to $102 \%$ in EWW for all compounds. The lowest absolute recoveries were obtained for the most lipophilic compounds, since their extraction during SPE was more problematic. However, extraction losses can be well compensated by the addition of deuterated IS as indicated by relative recoveries values summarized in Table 3. Relative recovery values are close to $100 \%$ for all compounds. Overall method intraday precision was evaluated in IWW and EWW as relative standard deviation (RSD \%) by spiking wastewater samples with 10 and $800 \mathrm{ng} / \mathrm{L}$ of each compound $(n=6)$. For both concentration levels and matrixes, RSD values were below $13 \%$ for all the compounds. These values were also improved with the use of IS (Table 3). The extent of matrix effects was evaluated during analysis. Matrix effects were assessed by dividing the response of the analytes in matrix-matched standards by the response in pure standard solution. Three different EWW and three IWW were tested. The obtained values (average) are shown in Table 3. For all the analytes in both matrixes, signal suppression was observed. It ranged from $-19 \%$ to $-50 \%$ in EWW. Higher suppression was observed in IWW with values ranging from $-23 \%$ to $-85 \%$.

Table 3

Performance of the LC-ESI-MS/MS method for the determination of new psychoactive substances in wastewater samples.

\begin{tabular}{|c|c|c|c|c|c|c|c|c|c|}
\hline & $\begin{array}{l}\text { Concentration le- } \\
\text { vel (ng/L) }\end{array}$ & $\begin{array}{l}\text { Absolute re- } \\
\text { covery }(\%) \\
(n=6) \\
( \pm \text { RSD } \%)\end{array}$ & $\begin{array}{l}\text { Relative re- } \\
\text { covery }(\%) \\
(n=6) \\
( \pm \text { RSD\% })\end{array}$ & $\begin{array}{l}\text { Concentration le- } \\
\text { vel (ng/L) }\end{array}$ & $\begin{array}{l}\text { Absolute re- } \\
\text { covery }(\%)(n=6) \\
( \pm \text { RSD } \%)\end{array}$ & $\begin{array}{l}\text { Relative re- } \\
\text { covery }(\%) \\
(n=6) \\
( \pm \text { RSD } \%)\end{array}$ & $\operatorname{ME}(\%)$ & $\begin{array}{l}\text { MLODs } \\
(\mathrm{ng} / \mathrm{L})\end{array}$ & $\begin{array}{l}\text { MLOQs } \\
\text { (ng/L) }\end{array}$ \\
\hline \multicolumn{10}{|l|}{$\begin{array}{l}\text { Influent } \\
\text { wastewater }\end{array}$} \\
\hline JWH-018 & 10 & $65( \pm 9)$ & $115( \pm 8)$ & 800 & $65( \pm 10)$ & $114( \pm 8)$ & -54 & 0.8 & 2.4 \\
\hline JWH-073 & 10 & $60( \pm 9)$ & $106( \pm 9)$ & 800 & $61( \pm 9)$ & $110( \pm 8)$ & -61 & 1.4 & 4.1 \\
\hline JWH-210 & 10 & $69( \pm 9)$ & $112( \pm 7)$ & 800 & $73( \pm 11)$ & $109( \pm 9)$ & -23 & 1.1 & 3.2 \\
\hline JWH-122 & 10 & $60( \pm 4)$ & $112( \pm 4)$ & 800 & $67( \pm 10)$ & $103( \pm 10)$ & -45 & 1.4 & 4.4 \\
\hline JWH-250 & 10 & $54( \pm 10)$ & $101( \pm 8)$ & 800 & $69( \pm 9)$ & $116( \pm 9)$ & -64 & 1.4 & 4.4 \\
\hline Mephedrone & 10 & - & - & 800 & $95( \pm 6)$ & $101( \pm 5)$ & -63 & 10 & 33 \\
\hline BZP & 10 & - & - & 800 & $61( \pm 9)$ & $104( \pm 5)$ & -85 & 20 & 67 \\
\hline MPPP & 10 & $109( \pm 4)$ & - & 800 & $97( \pm 7)$ & - & -60 & 3.0 & 10 \\
\hline a-PVP & 10 & $96( \pm 2)$ & - & 800 & $103( \pm 8)$ & - & -59 & 1.9 & 6.3 \\
\hline СР47,497 & 10 & - & - & 800 & $99( \pm 6)$ & - & -42 & 23 & 77 \\
\hline \multicolumn{10}{|l|}{$\begin{array}{l}\text { Effluent } \\
\text { wastewater }\end{array}$} \\
\hline JWH-018 & 10 & $44( \pm 8)$ & $121( \pm 7)$ & 800 & $50( \pm 6)$ & $85( \pm 5)$ & -45 & 0.7 & 2.0 \\
\hline JWH-073 & 10 & $44( \pm 9)$ & $101( \pm 7)$ & 800 & $51( \pm 5)$ & $99( \pm 4)$ & -32 & 1.2 & 3.8 \\
\hline JWH-210 & 10 & $40( \pm 7)$ & $118( \pm 5)$ & 800 & $51( \pm 9)$ & $82( \pm 7)$ & -33 & 0.5 & 1.5 \\
\hline JWH-122 & 10 & $40( \pm 9)$ & $106( \pm 8)$ & 800 & $57( \pm 9)$ & $89( \pm 8)$ & -50 & 0.3 & 0.9 \\
\hline JWH-250 & 10 & $46( \pm 6)$ & $113( \pm 6)$ & 800 & $61( \pm 8)$ & $107( \pm 6)$ & -23 & 0.5 & 1.6 \\
\hline Mephedrone & 10 & - & - & 800 & $99( \pm 6)$ & $110( \pm 4)$ & -35 & 5.0 & 17 \\
\hline BZP & 10 & - & - & 800 & $58( \pm 13)$ & $86( \pm 9)$ & -43 & 15 & 50 \\
\hline MPPP & 10 & $98( \pm 9)$ & - & 800 & $98( \pm 11)$ & - & -19 & 1.5 & 5.0 \\
\hline a-PVP & 10 & $98( \pm 4)$ & - & 800 & $102( \pm 8)$ & - & -25 & 1.5 & 5.0 \\
\hline СР47,497 & 10 & - & - & 800 & $91( \pm 10)$ & - & -20 & 18 & 60 \\
\hline
\end{tabular}

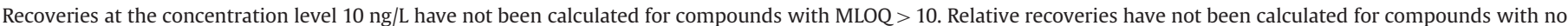
internal standard. 
Table 4

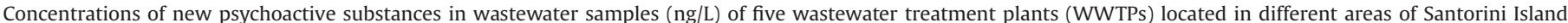
(Greece).

\begin{tabular}{|c|c|c|c|c|c|c|c|c|c|c|}
\hline & JWH-018 & JWH-073 & JWH-210 & JWH-122 & JWH-250 & Mephedrone & BZP & МРPР & a-PVP & СР47, 497 \\
\hline \multicolumn{11}{|c|}{ Influent wastewater } \\
\hline Kamari & n.d. & n.d. & 3.7 & $<$ LOQ & n.d. & n.d. & n.d. & n.d. & 6.5 & 79 \\
\hline Fira & n.d. & n.d. & n.d. & n.d. & n.d. & n.d. & n.d. & n.d. & $<\mathrm{LOQ}$ & $<\mathrm{LOQ}$ \\
\hline Karterados & n.d. & n.d. & n.d. & $<\mathrm{LOQ}$ & n.d. & n.d. & n.d. & n.d. & $<$ LOQ & 130 \\
\hline Emporio & n.d. & n.d. & $<$ LOQ & $<$ LOQ & n.d. & n.d. & n.d. & n.d. & n.d. & 305 \\
\hline Ia & n.d. & n.d. & n.d. & n.d & n.d. & n.d. & n.d. & n.d. & n.d. & $<$ LOQ \\
\hline \multicolumn{11}{|c|}{ Effluent wastewater } \\
\hline Kamari & n.d. & n.d. & 2.7 & 2.8 & n.d. & n.d. & n.d. & n.d. & n.d. & 60 \\
\hline Fira & n.d. & n.d. & 1.9 & 1.6 & n.d. & n.d. & n.d. & n.d. & n.d. & 223 \\
\hline Karterados & n.d. & n.d. & 2.4 & 4.1 & n.d. & n.d. & n.d. & n.d. & n.d. & 74 \\
\hline Emporio & n.d. & n.d. & 1.5 & 1.5 & n.d. & n.d. & n.d. & n.d. & n.d. & 176 \\
\hline Ia & n.d. & n.d. & $<$ LOQ & n.d. & n.d. & n.d. & n.d. & n.d. & n.d. & 78 \\
\hline
\end{tabular}

n.d.: not detected; < LOQ: below method limit of quantification.

\subsection{Application to real samples}

To demonstrate the suitability of the developed multi-residue methodology, the occurrence of the selected NPSs was evaluated in IWW and EWW grab samples of five different WWTP in Santorini Island, and also in grab IWW samples from Fira during seven different days, as described in Section 2.2.

Four out of the 10 evaluated NPSs were detected in at least one of the wastewater samples. Table 4 summarizes the concentrations values of the target compounds obtained in the grab samples of the five different WWTPs. The synthetic cannabinoids JWH-018, JWH-073 and JWH-250 were not detected either in IWW or EWW. The compounds JWH-210 and JWH-122 were detected in IWW and EWW at low levels, in the range <LOQ-4.1 ng/L. These low levels can be explained by the fact that synthetic cannabinoids undergo extensive metabolism within the body, leading to low levels of the parent compound present in urine [4]. Mephedrone, BZP and MPPP were also not detected in any sample while the pyrrolidinophenone a-PVP was detected in three IWW samples in the range 1.5-6.5 ng/L. CP47,497 was the compound detected at highest levels, from 60 up to $305 \mathrm{ng} / \mathrm{L}$, suggesting an important consumption of this substance. It is noteworthy that in some cases higher concentrations of CP47,497 were determined in EWW. This fact can be explained by the formation of unmeasured products of phase II human metabolism and/or transformation products (e.g. glucuronide conjugate, sulfates, glycinates) that during the wastewater treatment they hydrolyzed back to the parent compounds. Nevertheless, it is important to consider that the analyzed samples were grab samples and do not provide directly comparable results as can be obtained by analyzing composite samples.

The results of the evaluation of the occurrence of NPSs in IWW from Fira, the main city of Santorini Island, during seven consecutive days are displayed in Table S2 (this sampling was conducted on different dates that the results shown in Table 4). The synthetic cannabinoids JWH-018, JWH-073 and JWH-250 were not detected in any sample, while JWH-210 and JWH-122 were detected in two and one sample, respectively, at low concentrations (below MLOQs and $4.5 \mathrm{ng} / \mathrm{L}$ ). These results are in agreement with those obtained for the grab samples described in Table 4. On the contrary, a-PVP was not detected in any sample. MPPP and the stimulant mephedrone (which was detected at low levels in Cambridgeshire (U.K.) in a previous study [36]) were also not detected. BZP remained undetected, in contrast with high frequencies of detection determined in previous reports carried out in the U.K. [19,37]. High levels found for CP47,497 (89-634 ng/L) are notable, with high differences among the evaluated days. Results for this compound did not show a clear trend of use during the evaluated period, but showed a high use of this substance. Differences in the concentration ranges between the two different monitoring studies can be explained by the fact that the samples consisted of grab samples. Although the results do not allow firm conclusions, a constant use of some of the determined NPSs, such as $\mathrm{CP} 47,497$, was clearly observed. This compound is present in different herbal mixtures (e.g. Spice) and other products (bath salts or incense) and it is frequently mixed with other synthetic cannabinoids [38]. Currently no legislation exists regarding this substance in Greece.

\section{Conclusions}

An analytical method for the simultaneous determination of 10 NPSs, based on SPE cleanup and LC-MS/MS analysis, was developed, optimized and validated for the determination of these compounds in IWW and EWW.

Factors such as the selection of the chromatographic column or the performance of the SPE cleanup were studied in detail. The use of PolyClean 2H SPE cartridges and a PFP column provided the best method performance. Despite the difficulties due to the wide range of physicochemical properties of the target analytes, the developed methodology is efficient, accurate and allows a reliable determination of the selected NPSs in the low ng/L level, being suitable to perform monitoring studies of the target analytes in wastewater samples.

The proposed methodology was successfully applied for the determination of NPSs in IWW and EWW samples from several WWTPs in Santorini Island (Greece), where four out of the 10 selected analytes were detected at least in one sample, showing a relevant use of these substances in the studied areas. Eight of the 10 target analytes were investigated in wastewater for the first time and the compounds a-PVP, CP47,497, JWH-122 and JWH-210 were detected for the first time in influents and effluents.

These results also confirm that the analysis of NPSs in wastewater is a powerful tool that can provide valuable information on patterns of use of these substances. There is a need of developing new analytical methodologies with higher number of NPSs in order to obtain the whole picture of the use of drugs of abuse.

\section{Acknowledgments}

This project was implemented under the Operational Program "Education and Lifelong Learning» and funded by the European 
Union (European Social Fund) and National Resources - ARISTEIA 624.

\section{Appendix A. Supplementary material}

Supplementary data associated with this article can be found in the online version at http://dx.doi.org/10.1016/j.talanta.2015.06. 080.

\section{References}

[1] Monitoring New Drugs, EMCDDA, Lisbon, April 2006 http://www.emcdda. europa.eu/html.cfm/index40105EN.html (accessed 10.5.15).

[2] M.R. Meyer, Trends in analyzing emerging drugs of abuse - from seized samples to body samples, Anal. Bioanal. Chem. 406 (2014) 6105-6110.

[3] M. Ibáñez, J.V. Sancho, L. Bijlsma, A.L. van Nuijs, A. Covaci, F. Hernández, Comprehensive analytical strategies based on high-resolution time-of-flight mass spectrometry to identify new psychoactive substances, Trends Anal. Chem. 57 (2014) 107-117.

[4] I. Vardakou, C. Pistos, C. Spiliopoulou, Spice drugs as a new trend: mode of action, identification and legislation, Toxicol. Lett. 197 (2010) 157-162.

[5] M.J. Reid, L. Derry, K.V. Thomas, Analysis of new classes of recreational drugs in sewage: synthetic cannabinoids and amphetamine-like substances, Drug Test. Anal. 6 (2014) 72-79.

[6] J. Van Amsterdam, D. Nutt, W. Van den Brink, Generic legislation of new psychoactive drugs, J. Psychopharmacol. 27 (2013) 317-324.

[7] K. Brennan, A. Johnstone, P. Fitzmaurice, R. Lea, S. Schenk, Chronic benzylpiperazine (BZP) exposure produces behavioral sensitization and cross-sensitization to methamphetamine (MA), Drug Alcohol Depend. 88 (2007) 204-213.

[8] O. Corazza, Z. Demetrovics, W. Van den Brink, F. Schifano, 'Legal highs' an inappropriate term for 'Novel Psychoactive Drugs' in drug prevention and scientific debate, Int. J. Drug Policy 24 (2012) 82-83.

[9] D.E. Nichols, W.E. Fantegrossi, The effects of drug abuse on the human nervous system, in: M. Kuhar, B. Madras (Eds.), Emerging Designer Drugs, vol. 19, Elsevier, New York, 2013, pp. 575-596.

[10] Perspectives on Drugs/Controlling New Psychoactive Substances, EMCDDA2013, 〈http://www.emcdda.europa.eu/topics/pods/controlling-new-psychoactive-substances $\rangle$ (accessed 28.09.14).

[11] C. Chen, C. Kostakis, R.J. Irvine, J.M. White, Increases in use of novel synthetic stimulant are not directly linked to decreased use of 3,4-methylenedioxy-Nmethylamphetamine (MDMA), Forensic Sci. Int. 231 (2013) 278-283.

[12] P. Gee, S. Richardson, W. Woltersdorf, G. Moore, Toxic effects of BZP-based herbal party pills in humans: a prospective study in Christchurch, New Zealand,, N. Z. Med. J. 118 (2005) 35-44.

[13] D.M. Wood, J. Button, S. Lidder, J. Ramsey, D.W. Holt, P.I. Dargan, Dissociative and sympathomimetic toxicity associated with recreational use of 1-(3-trifluoromethylphenyl) piperazine (TFMPP) and 1-benzylpiperzine (BZP), J. Med Toxicol. 4 (2008) 254-257.

[14] P.I. Dargan, R. Sedefov, A. Gallegos, D.M. Wood, The pharmacology and toxicology of the synthetic cathinonemephedrone (4-methylmethcathinone), Drug Test. Anal. 3 (2011) 454-463.

[15] J.P. Kelly, Cathinone derivatives: a review of their chemistry, pharmacology and toxicology, Drug Test. Anal. 3 (2011) 439-453.

[16] New Psychoactive Substances in Europe. An Update from the EU Early Warning System, EMCDDA, Lisbon, March 2015, 〈http://www.emcdda.europa. eu/publications/2015/new-psychoactive-substances $\rangle$ (accessed 10.05.15).

[17] European Drug Report, 2014: Trends and Developments, 〈http://www.emcdda. europa.eu/edr2014 (September 2014)

[18] K.V. Thomas, L. Bijlsma, S. Castiglioni, A. Covaci, E. Emke, R. Grabic, F. Hernández, S. Karolak, B. Kasprzyk-Hordern, R.H. Lindberg, M. Lopez de Alda, A. Meierjohann, C. Ort, Y. Pico, J.B. Quintana, M. Reid, J. Rieckermann, S. Terzic, A.L. van Nuijs, P. de Voogt, Comparing illicit drug use in 19 European cities through sewage analysis, Sci. Total Environ. 432 (2012) 432-439.

[19] D.R. Baker, B. Kasprzyk-Hordern, Multi-residue analysis of drugs of abuse in wastewater and surface water by solid-phase extraction and liquid chromatography-positive electrospray ionisation tandem mass spectrometry, J. Chromatogr. A 1218 (2011) 1620-1631.

[20] E. Mwenesongole, L. Gautam, S. Hall, J. Waterhouse, M. Cole, Simultaneous detection of controlled substances in waste water, Anal. Methods 5 (2013) 3248-3254.

[21] A.L. Van Nuijs, A. Gheorghe, P.G. Jorens, K. Maudens, H. Neels, A. Covaci, Optimization, validation, and the application of liquid chromatography-tandem mass spectrometry for the analysis of new drugs of abuse in wastewater, Drug Test. Anal. 6 (2014) 861-867.

[22] Press Announcement Regarding EKTEPN Meeting for "New Substances, New Challenges" 〈http://www.ektepn.gr/index.php 〉; Greek Monitoring Centre for Drugs (EKTEPN).

[23] Europol-EMCDDA, Joint Report on a New Psychoactive Substance: 1-benzylpiperazine (BZP).1.

[24] J. Teske, J.P. Weller, A. Fieguth, T. Rothamel, Y. Schulz, Hans D. Troge, Sensitive and rapid quantification of the cannabinoid receptor agonist naphthalen-1-yl(1-pentylindol-3-yl)methanone (JWH-018) in human serum by liquid chromatography-tandem mass spectrometry, J. Chromatogr. B 878 (2010) 2659-2663.

[25] U. Antia, H.S. Lee, R.R. Kydd, M.D. Tingle, B.R. Russell, Pharmacokinetics of 'party pill' drug N-benzylpiperazine (BZP) in healthy human participants, Forensic Sci. Int. 186 (2009) 63-67.

[26] M. Hutter, S. Kneisel, V. Auwärter, M.A. Neukamm, Determination of 22 synthetic cannabinoids in human hair by liquid chromatography-tandem mass spectrometry, J. Chromatogr. B 903 (2012) 95-101.

[27] M. Jang, W. Yang, H. Choi, H. Chang, S. Lee, E. Kim, H. Chung, Monitoring of urinary metabolites of JWH-018 and JWH-073 in legal cases, Forensic Sci. Int. 231 (2013) 13-19.

[28] S. Kneisel, V. Auwärter, Analysis of 30 synthetic cannabinoids in serum by liquid chromatography-electrospray ionization tandem mass spectrometry after liquid-liquid extraction. J. Mass Spectrom. 47 (2012) 825-835.

[29] S.S. Tuv, H. Krabseth, R. Karinen, K.M. Olsen, E.L. Øiestad, V. Vindenes, Prevalence of synthetic cannabinoids in blood samples from Norwegian drivers suspected of impaired driving during a sevenweeks period, Accid. Anal. Prev. 62 (2014) 26-31.

[30] V.L. Borova, N.C. Maragou, P. Gago-Ferrero, C. Pistos, N.S. Thomaidis, Highly sensitive determination of 68 psychoactive pharmaceuticals, illicit drugs, and related human metabolites in wastewater by liquid chromatography-tandem mass spectrometry, Anal. Bioanal. Chem. 406 (2014) 4273-4285.

[31] /http://www.waters.com/webassets/cms/events/docs/hplccolumnbrochure720003995en.pdf $\rangle$, September 2014.

[32] 〈http://www.phenomenex.com/Info/WebDocumentServe/reversedguide.pdf $\rangle$, September 2014.

[33] S. Hudson, J. Ramsey, The emergence and analysis of synthetic cannabinoids, Drug Test. Anal. 3 (2011) 466-478.

[34] C. Sauer, F.T. Peters, C. Haas, M.R. Meyer, G. Fritschi, H.H. Maurer, New designer drug $\alpha$-pyrrolidinovalerophenone (PVP): studies on its metabolism and toxicological detection in rat urine using gas chromatographic/mass spectrometric techniques, J. Mass Spectrom. 44 (2009) 952-964.

[35] A.J. Pedersen, L.A. Reitzel, S. Stybe Johansen, K. Linnet, In vitro metabolism studies on mephedrone and analysis of forensic cases, Drug Test. Anal. 5 (2012) 430-438.

[36] N. Uchiyama, R. Kikura-Hanajiri, J. Ogata, Y. Goda, Chemical analysis of synthetic cannabinoids as designer drugs in herbal products, Forensic Sci. Int. 198 (2010) 31-38.

[37] D.R. Baker, B. Kasprzyk-Hordern, Spatial and temporal occurrence of pharmaceuticals and illicit drugs in the aqueous environment and during wastewater treatment: new developments, Sci. Total Environ. 454-455 (2013) 442-456.

[38] V. Auwärter, S. Dresen, W. Weinmann, M. Müller, M. Pütz, N. Ferreirós, 'Spice’ and other herbal blends: harmless incense or cannabinoid designer drugs? J. Mass Spectrom. 44 (2009) 832-837. 